\title{
Grande, só o Brasil: As regiões platina e amazônica no centro do pensamento geoestratégico do Estado
}

\section{Great, only Brazil: Platine and Amazonian regions at the center of geostrategic state thinking}

Rev. Bras. Est. Def. v. 5, nº 1, jan./jun. 2018, p. 115-138

\section{ADRIANO MOURA OLIVEIRA}

\section{INTRODUÇÃO}

Se a construção de Brasília, A capital Geopolítica (Vesentini 1987), na segunda metade da década de 1950, é um exemplo emblemático do imbricamento das questões políticas e geográficas que envolveram a transferência da capital sob o escopo de traçar diretrizes estratégicas para o exercício do poder, a força do discurso geopolítico, como inspirador de políticas e ações, já se fazia presente na década de 1930 com a instauração do Estado Novo, não somente na criação de órgãos ligados ao exército e especializados em análises geográficas (como o Conselho Nacional de Estatística de 1931, o Serviço Geográfico e Histórico do Exército em 1932 e, em 1934, o Conselho Brasileiro de Geografia), mas também na busca de instrumentos que permitissem levar adiante uma ação "modernizadora", incluindo - perante uma nova gestão territorial - o interesse de pôr fim "aos regionalismos desenfreados que comprometiam a todo o momento a integridade nacional" (Schwartzmam, Bomeny e Costa 1984, 21).

A preocupação com a integração nacional, com a unidade territorial e com a ocupação fronteiriça sempre estiveram presentes e ocuparam um papel de destaque no pensamento geopolítico militar predominante em boa parte de história republicana brasileira e que, integrado nos anos 1920 aos círculos de pensamentos oficiais, ecoou até a década de 1970, no auge da Ditatura Militar. Esse pensamento geopolítico reflete a preocupação com o problema da unidade nacional, segundo a ideia corrente de que uma grande extensão territorial só se torna uma vantagem política e econômica

Adriano Moura Oliveira - Doutorado em andamento pela Universidade Federal do Rio de Janeiro (UFRJ). 
quando associada à ocupação e ao povoamento adequados. No centro dos maiores debates sobre geopolítica, indiscutivelmente, as regiões da Bacia do Prata e da Bacia Amazônica cumpriam esses requisitos no território brasileiro, bem como no pensamento geopolítico militar.

O Brasil Amazônico se comunica de modo mais direto com o oceano, por isso se dispõe do Rio Amazonas como via natural. E sua capacidade de penetração a mais ampla, pois o vale amazônico é o grande coletor do formidável anfiteatro que se arqueia de Caracas a La Paz. O Brasil Platino, apesar de que exija meios artificiais para ligar-se ao oceano, dispõe de portos com suficiente capacidade de atração na costa e dos estímulos de dois países mediterrâneos que naturalmente reagem contra a força centrípeta do Prata: o sul de Mato Grosso, prolongando os territórios paulista e paranaense, representa a sua força de penetração. Quer dizer que excentricamente, por via marítima, ou concentricamente, por vias terrestres, o papel funcional dessas regiões é de ligar, homogeneizar, amarrar os dois Brasis essenciais, do ponto de vista continental, o platino e o amazônico (Travassos 1947, 129-131).

As regiões da Bacia do Prata e da Bacia Amazônica foram alvo das primeiras investidas do governo Getúlio Vargas. Deste modo, pelo menos intencionalmente, a "Marcha para o Oeste" proposta por esse governo, formaria um conjunto de ações governamentais bastante variadas, que iam desde a implantação de colônias agrícolas, passando pela abertura de novas estradas, até obras de saneamento rural, traduzindo-se numa política expansionista que buscava a integração nacional e, concomitantemente, a organização dos territórios, garantindo, em tese, além da segurança e da efetiva posse, a exploração produtiva de imensas regiões fronteiriças praticamente inabitadas. A incorporação de novas regiões ao circuito produtivo nacional, orientada para a formação de um mercado nacional integrado aos centros dinâmicos da economia nacional, trouxe à tona um caráter bem especifico do discurso de "integração", uma vez que, do ponto de vista ideológico - tanto nas esferas do governo, quanto nos círculos militares - integrar significava, sobretudo, garantir a soberania para a projeção externa, isto é, para a construção de uma potência:

O imperialismo do Brasil consiste em ampliar as suas fronteiras econômicas e integrar um sistema coerente, em que a circulação das riquezas e utilidades se faça livre e rapidamente, baseada em meios de transportes eficientes, que aniquilarão as forças desintegradoras da nacionalidade. O sertão, o isolamento, a falta de contato são os únicos inimigos terríveis para a integridade do país. Os localismos, as tendências centrífugas são resultado da formação estanque de eco- 
nomias regionais fechadas. Desde que o mercado nacional tenha a sua unidade assegurada, acrescendo-se a sua capacidade de absorção, estará solidificada a federação política. A expansão econômica trará o equilíbrio desejado entre as diversas regiões do país, evitando-se que existam irmãos ricos ao lado de irmão pobres. No momento nacional só a existência de um governo central, forte, dotado de recursos suficientes, poderá trazer o resultado desejado (Capanema apud Schwartzman 1984, 422-423).

Este artigo tem como objetivo, através da análise do conjunto de ideias apresentadas por militares em diferentes momentos, demonstrar que a configuração de um pensamento geopolítico brasileiro de potência, se deu num constructo que equacionava as questões de segurança interno-externa à ideia de um desenvolvimento possível a partir das potencialidades e posição geográfica do Estado. Se de um lado a geopolítica brasileira remetia às influências vindas de fora, de outro, trazia como especificidade a identificação das regiões platina e amazônica, como centro de um projeto de potência, o coração do continente, cujo domínio se fazia indispensável.

Neste cenário situam-se nomes como de Everardo Backheuser, do brigadeiro Lysias Rodrigues, do Capitão Mario Travassos e o do general Golbery do Couto e Silva. Ligados diretamente aos círculos do pensamento militar, esses autores expressavam fundamentalmente em suas ideias a preocupação em relação à posição brasileira em face do conjunto de Estados sul-americanos e a projeção do Estado nessa região. Deste modo, ideias ligadas à projeção externa apareciam entrelaçadas a temas como coesão nacional e integração regional. O termo coesão interna, aliás, sofreu modificações e se consolidou na literatura especializada nos anos posteriores. Porém, em 1933, quando Backheuser (1933) apresentou seu trabalho Problemas do Brasil - Estrutura geopolítica, "coesão" basicamente fazia referência, para não dizer apologia, a um estado ditatorial, centralizador e coercitivo como forma de promover o desenvolvimento.

Lysias Rodrigues, também aplaudia a centralização do poder, tanto por vias autoritárias quanto pela mudança da capital federal para o interior do país. Como é de conhecimento, a mudança da capital visava, pela ação planejadora, sobretudo, "impedir o crescimento dos movimentos populares", como forma de centralizar e racionalizar o capitalismo brasileiro direcionado pela burguesia nacional e pelo capital estrangeiro. Colocado como um problema essencialmente geopolítico ao tratar da integração nacional, Lysias Rodrigues exprime declaradamente o sonho de grandeza nacional:

A impossibilidade material de estabelecer uma densa rede de ferro e rodovias é substituída inteligentemente pela rede de aerovias, que 
rapidamente cobre todo o país; a dificuldade de estender fios telegráficos por todo o território nacional é suprida com a implantação de postos radiotelegráficos por toda parte. Estimulou-se a navegação marítima e fluvial, organizaram-se os planos nacionais ferroviários e rodoviário, ao mesmo tempo em que uma centralização enérgica era desenvolvida pelo Governo Federal, cortando uns regionalismos doentios, coibindo expansões políticas absolutas, estabelecendo uma só bandeira, a nacional, um só hino, o do país, sob a mística soberana: "Grande, só o Brasil” (Rodrigues 1947, 57).

\section{UMA GEOPOLÍTICA DE POTÊNCIA NO CORAÇÃO DO CONTINENTE}

O arranjo interno do Estado deveria servir como trampolim para a tão sonhada projeção externa do Brasil. Rodrigues iria expressar essa posição com força em seus trabalhos, porém, influenciado diretamente por aquilo que absorveu de seu predecessor e colega de farda, o capitão Mário Travassos. Operando nesse chão histórico, ou seja, assentado num pensamento geopolítico de integração e unidade nacional, a obra de Travassos é considerada por aqueles que se dedicam ao assunto como um marco na formação da geopolítica brasileira; fortemente influenciado pelas ideias de Mackinder, ${ }^{1}$ o poder terrestre brasileiro foi o foco de atenção em todo o trabalho. O livro do capitão foi produzido e chegou ao público logo após a revolução de 1930 e, de acordo com as produções mais atuais da ESG, o livro é classificado como o "primeiro ensaio geopolítico do Brasil”, recebeu o título original de "Aspectos geográficos sul-americanos" e exerceu uma influência teórica seminal sobre o pensamento estratégico brasileiro.

A leitura de algumas páginas escritas por Mário Travassos em tempos tão recuados suscita ainda hoje o interesse geral e mostra uma iluminadora perspectiva dos fatos dominantes da conjuntura sul americana: - "O enquadramento da massa continental por dois oceanos diferentes - a Leste o Atlântico, a oeste o Pacifico; a oposição sistematizada por circunstâncias decisivas, entre as duas maiores bacias hidrográficas do continente, ambas na vertente atlântica - a do Amazonas ao norte e a do Prata ao sul; a existência de países mediterrâneos - o caso da Bolívia e do Paraguai - justo na região em que aqueles antagonismos como que se encontram, constituem os fatos essenciais à eclosão de fenômenos geopolíticos da mais extensa e profunda repercussão continental”. O impacto dessa obra foi imenso pelas questões candentes que desvelava de um aspecto central do poder regional, cujas repercussões atravessaram décadas, projetando-se além do século em que foram pensadas e meditadas. De maneira a se 
encontrarem presentes nos dramas, mas também nas oportunidades que se abrem à integração continental e a emergência de um poder capaz de transformar o poder mundial (Cabral 2000, 13).

É sabido que Harold Mackinder trazia como alvo basilar de seu postulado a dominação de pontos essenciais em um território, na garantia de manter no mesmo um poder constituído. Essas teorias foram reorganizadas, em parte, para atender aquilo que Travassos classificou como peculiaridades do continente sul-americano; fundamentalmente a preocupação estava na posição brasileira em face ao conjunto de Estados sul-americanos e a projeção do Estado nessa região, frente a seu vizinho, leia-se inimigo, Argentina. Nesse esforço, o planalto boliviano assumiu o papel de território chave, entendido como Heartland ou coração do continente. Segundo Travassos, o controle dessa faixa garantira ao Brasil o domínio político/econômico sul-americano, isto é, a existência de países mediterrâneos - o caso da Bolívia e do Paraguai - justo na região em que aqueles antagonismos se encontram, constituem os fatos essenciais à eclosão de fenômenos geopolíticos da mais extensa e profunda repercussão continental (Travassos 1947, 8)

A análise erigida por Travassos pressupõe que todos os problemas correntes no continente naquele momento só poderiam ser apreendidos a partir do entendimento de que estavam assentados sob dois grandes antagonismos geográficos: Atlântico contra Pacífico e Amazonas - coração dos interesses estratégicos - contra região da Prata. O primeiro antagonismo centrava-se na oposição entre os dois oceanos que envolviam a "massa" sul-americana, cortada pela cordilheira dos Andes. Não mostrando muita clareza nesse ponto, Travassos dizia que a cordilheira garantiria à parte atlântica um papel dominante, não só na região, mas também no eixo da civilização ocidental - como canal de comunicação entre o nosso continente e o europeu.

Em resumo, na vertente atlântica, imensa superfície de contato com os mais possantes centros da civilização mundial, vias de penetração naturais estendendo-se do oceano às próprias fraldas andinas. Mentalidade agrícola, tendências dinâmicas; na vertente pacífica, isolamento marítimo relativo, produção e comunicações que aconchegam características montanhosas, mentalidade mineira, tendências estáticas. Recapitulamos o formidável antagonismo demarcado pelas cumeadas dos Andes, porque da maneira de ser da oposição entre as vertentes andinas pode-se concluir da influência decisiva da vertente atlântica sobre a vertente pacífica, da sorte de sucção econômica que o sistema hidrográfico daquela, acionada como se encontra pelas correntes de transporte marítimo mais importante do globo, há de exercer sobre esta (Travassos 1947, 71-72). 
O primeiro antagonismo não exprime grande clareza, porém aquilo que dele emana é o papel assumido pelo Brasil como força continental. Deixando de lado as elucubrações geoestratégicas, temos uma visão do país como uma nação independente, voltada principalmente às nações europeias; lembremos que o momento em que estão inscritas essas ideias, ainda vigorava uma indefinição em relação para onde devia olhar o Estado, nutria-se muita admiração pelos modelos fascistas que se edificavam na Europa, ao mesmo tempo em que internamente se processava uma centralização do poder estatal a partir de 1930. Foi assim, pensando em termos expansivos - no qual o exemplo europeu cabia muito bem - que o segundo antagonismo proposto se referia à oposição entre o Amazonas e o rio da Prata, tida pela geopolítica como dois grandes sistemas fluviais, entretanto opostos; um deságua ao sul e o outro ao norte da vertente atlântica. Isso expressaria o embate entre a região do Prata e da Amazônia controladas nessa ordem pela Argentina e Brasil. De acordo com o autor, o controle dessa região, por ser a principal via de comunicação do Pacífico, garantiria a seu condutor o acesso irrestrito à civilização mundial.

Daí o papel importantíssimo do controle boliviano, para garantir que esse privilégio estivesse nas mãos do Brasil e não da Argentina. Ao deter-se sobre o tema de uma política expansionista argentina, Travassos afirmou que a prova de tal prospecção expansionista estaria na enorme rede ferroviária argentina, que estabelecia uma ligação entre Buenos Aires e as capitais de três países limítrofes: Assunção, Santiago e La Paz. De acordo com o autor, o perigo maior estaria na intersecção entre Buenos Aires e La Paz, isto é, a preocupação era que essa comunicação, colocasse em risco o heartland boliviano - do qual o Brasil deveria se apossar - criando uma situação onde os antagonismos (Atlântico versus Pacífico e Amazonas versus Prata) pudessem favorecer a Argentina na competição pela hegemonia no continente. Mário Travassos via no heartland uma opção única para o projeto de potência brasileiro, assim como enxergava no planalto boliviano o instrumento inicial de toda a escalada nacional. De modo incisivo, esse caráter foi exposto como mostramos:

As solicitações que cercam o território boliviano são de tal monta que chegam a criar para a Bolívia uma instabilidade política verdadeiramente ameaçadora da paz sul-americana. Com efeito, vinculada ao território do pacífico pela contextura andina da parte ocidental de seu território é, em seguida, em sua parte central e oriental, violentamente dissociada pela repulsão das bacias platina e amazônica. (...) Poderíamos dizer que para a política brasileira a Bolívia deste século é o Uruguai do século passado, agravadas as questões pela colocação desse foco de controvérsias políticas sobre o próprio flanco 
de território brasileiro em sua parte mais sensível, dada a natureza viva de nossas fronteiras sudeste e sul. E para completar esse esboço é preciso que não se esqueça do território paraguaio, sorte de prolongamento de toda a angústia concentrada no território boliviano. (...) O território boliviano pode ser considerado como o centro geográfico do continente sul-americano, seja por sua posição como explosão oriental dos mais importantes contrafortes da cordilheira, seja como ponte ortográfica abrindo o sistema andino, simultaneamente, as influências político-econômicas que as bacias do amazonas e do Prata representam na massa continental (Travassos 1947,97-32).

Façamos uma pausa à reflexão. Está claro que o discurso geopolítico proferido por Travassos diz respeito, em sua totalidade, aos objetivos expansionistas do Estado brasileiro. Entretanto, diferentemente do quadro apocalíptico de inimizade descrito por Travassos, as relações entre Brasil e Argentina na década de 1930, como afirma Monica Hirst (Hirst; Russell, 1987), do ponto de vista da história diplomática, se inscreve num arrolamento de cooperação, enriquecimento e diversidade da agenda bilateral. Em 1935, o Presidente Getúlio Vargas em visita a Buenos Aires, em retribuição à visita do chefe de Estado argentino realizada em 1933, firmou uma série de importantes convênios, tal como o Pacto Antibélico de Não Agressão e de Conciliação assinado na primeira visita - os acordos ficavam abertos à adesão de outros países da região. Esse é um dos traços mais relevantes dos entendimentos formais entre Brasil e Argentina, que revela o potencial estruturante regional contido na relação bilateral. Então, onde Travassos identificava um problema nessas relações aparentemente de cooperação? Onde estariam, como afirmou o autor, os reflexos de uma instabilidade geográfica de âmbito internacional, gerada pela disputa de poder entre Brasil e Argentina? E, sobretudo, onde se insere a Bolívia nesse constructo?

Podemos arriscar um ponto em questão. A visita de Getúlio Vargas à Argentina se deu em consonância com a Conferência Comercial PanAmericana e precedeu, em poucas semanas, à assinatura do Protocolo de Paz que pôs fim à Guerra do Chaco entre Paraguai e Bolívia (1932-1935) (Bastos 2001). O processo de paz no Chaco deu lugar a uma estreita concertação entre Brasil e Argentina, que atuaram como mediadores, contrariando a intenção de Washington de instaurar um procedimento arbitral em mãos de um bloco dirigido pelos Estados Unidos.

Do lado argentino, essa política respondia aos esforços de aproximação com outros países da região como condição de ampliar a influência e articular alianças regionais em virtude das tensas relações com os EUA 
- tensões aprofundadas pela sistemática reafirmação da posição da GrãBretanha como aliada privilegiada do país platino, em uma área em que os EUA visavam consolidar sua hegemonia.

Pelo lado brasileiro, o posicionamento contrário no Chaco também atendia a uma política de autonomia e consolidação regional de um poder. Porém, diferente da vizinha Argentina, o Estado brasileiro estava - muito em fator da política de boa vizinhança - atrelado aos Estados Unidos, e essa suposta "autonomia" regional tinha limites claros; mesmo assim, nesse aspecto, a disputa de espaço entre Brasil e Argentina foi acirrada, apesar do incremento dos laços comerciais. A rivalidade entre ambos e a pretensão de se tornarem potências regionais condicionaram a política dos dois países (Bandeira 1993).

Nesse sentido, ganha destaque a preocupação que Travassos externaria entre Bolívia e Paraguai, isto é, os bolivianos tinham a parte ocidental de seu território cindido à cordilheira dos Andes e sua região oriental, oscilando entre as bacias amazônica e platina. Essa oscilação se processaria pelos polos de atração entre Brasil e Argentina - este último, aliás, o maior beneficiário da instabilidade boliviana, já que a Bolívia dependia dos argentinos, especificamente dos portos, para escoar sua produção. A solução para esse problema, apresentada por Travassos, era que o Brasil, em um esforço político, acabasse com a dependência boliviana do território argentino; para isso seria necessário a criação de canais de escoamento, como uma rede fluvial que ligasse a Bolívia à bacia amazônica e terrestre, de ligação entre a Amazônia até o porto de Santos.

E de todo esse exame pode-se fixar de modo categórico o sentido político da Bolívia como centro geográfico do continente e a causa eventual de conflito armado, cujo vulto poderá mesmo assumir o caráter de verdadeira conflagração. [...] A oscilação entre as forças político-econômicas que as bacias do amazonas e do prata representam, essa sim pode traduzir verdadeiro motivo de apreensões internacionais mais sérias. Essas bacias significam interesses de toda sorte, ligados às duas mais importantes nações do continente, que, se tudo as une, nem por isso estão de todo livres de possíveis estremecimentos provindos do planalto central do continente. E nisso não está todo o perigo, pois, se essas nações se estremecerem, é cer to que esse estremecimento terá imediata repercussão continental que poderá resultar como consequência da instabilidade geográfica da Bolívia (Travassos 1947, 89-90).

Desnecessário caracterizar cada uma das inquietações apresentadas por Travassos, uma vez que todas elas operam na esfera das relações entre Brasil e Argentina. Os dois Estados são vistos como nações hegemônicas 
em potencial dentro do continente e, consequentemente, todas as manifestações de relações internacionais são entendidas como políticas estatais de conotação imperialista. O território que abrange o Brasil é delimitado por dois tipos condicionantes, uma geográfica e outra política; de um lado, como já dito, estamos situados na vertente atlântica - bacias amazônica e platina. De outro, o Estado faz fronteira com outros dez países. A primeira etapa de análise de Travassos diz respeito à posição territorial, isto é, o Brasil é dividido em quatro grandes regiões, sendo elas: o Brasil amazônico, o nordeste subequatorial, a vertente oriental dos planaltos e, mais uma vez, o Brasil platino, cada uma com características bem distintas.

[...] o Brasil Amazônico comportando a região serrana (maciço granítico das Guianas), a depressão amazônica (calhas do Amazonas e seus afluentes) e a Hiléia (região das matas); o Nordeste Subequatorial abrangendo o Golfão Maranhense (sorte de transição da Amazônia), a bacia do Parnaíba, as Serras e Chapadas da Vertente Norte-Oriental (regiões semiáridas), o litoral, a mata e o agreste de Pernambuco (balizada pelo Cabo de S. Roque, foz do S. Francisco e Serra da Borborema); a Vertente Oriental dos Planaltos compreendendo o litoral baiano-espírito-santense (inclusive as bacias do Paraguaçu, Jequitinhonha e Doce) e a região das chapadas (zona alta), o vale do S. Francisco, o sul Mineiro e o vale do Paraíba; o Brasil Platino englobando a costa ou contra-vertente oceânica (entre o Atlântico e a Serra do Mar), a Região Serrana (Serra do Mar e Geral), a região do Planalto (alternação de campos e matas, região suporte dos afluentes orientais do Paraná), a campanha rio-grandense e a baixada mato-grossense - em seu conjunto, nada mais espontâneo que essas grandes divisões e respectivas subdivisões (Travassos 1947,127-128).

Não tem significação alguma a descrição do autor se não levarmos em consideração suas intenções de posicionar o Brasil no centro do continente; isto posto, ao analisar as regiões brasileiras - novamente influenciadas pelo embate Brasil-Argentina - o militar identificou a existências de "dois países” dentro do mesmo Brasil, o amazônico e o platino. Diz Travassos:

O Brasil Amazônico se comunica de modo mais direto com o oceano, por isso se dispõe do Rio Amazonas como via natural. E sua capacidade de penetração a mais ampla, pois o vale amazônico é o grande coletor do formidável anfiteatro que se arqueia de Caracas a La Paz. O Brasil Platino, apesar de que exija meios artificiais para ligar-se ao oceano, dispões de portos com suficiente capacidade de atração na costa e dos estímulos de dois países mediterrâneos que naturalmente reagem contra a força centrípeta do Prata: o sul de Mato-Grosso, 
prolongando os territórios paulista e paranaense, representa a sua força de penetração. Quer dizer que excentricamente, por via marítima, ou concentricamente, por vias terrestres, o papel funcional dessas regiões é de ligar, homogeneizar, amarrar os dois Brasis essenciais, do ponto de vista continental, o platino e o amazônico (Travassos 1947, 129-131).

Esses documentos expressam uma visão desses "Brasis", tanto amazônico como platino, ${ }^{2}$ como regiões que convergem suas potencialidades no planalto boliviano, ou seja, a formação de uma unidade nacional tão perseguida passaria por políticas que consolidassem a ligação e o desenvolvimento das regiões afastadas, a exemplo das quatro citadas, além de um empenho geopolítico conjunto para transformar os objetivos de conquista do heartland boliviano. A partir desse momento, a projeção do Brasil no continente começava a se delinear. Dizia ele:

O fato decisivo, quando se olha para o conjunto do território brasileiro, engastado na massa continental sul-americana, reside nas notáveis possibilidades viárias, já em franca manifestação prática, que se traduzem, quer na naturalização do poder concêntrico na bacia platina, quer na força de atração do Amazonas, quer na capacidade coordenadora do litoral atlântico em relação a ambas essas altas manifestações de potencial econômico e político que o Brasil tem em suas mãos (Travassos 1947, 145-146).

Resumidamente, a geopolítica de Travassos propunha, no plano externo, ações expansionistas no continente baseadas em políticas que aproximassem o Brasil de países considerados indispensáveis do ponto de vista estratégico e comercial. Internamente, essas ações visavam uma integração nacional baseada numa diversificada política de comunicações, como a resolução das contradições Atlântico-Pacífico através da transferência "de parte da riqueza da vertente ocidental para a vertente oriental”.

Temos a posse da maior parte da bacia amazônica e com ela o controle de todas as suas possibilidades viatórias, inclusive sobre os transportes que venham da outra vertente continental. Poderemos ter, em consequência da parte sul de nosso litoral e das possibilidades de linhas de penetração para oeste, marcada influência neutralizadora das atuações político-econômicas da bacia platina. E, em virtude de nosso extenso litoral, podemos amarrar todas as manifestações daquele controle e desta influência, emprestando-lhes a necessária coesão. [...] Examinadas, e consequentemente admitidas, certas manifestações geográficas da massa continental sul-americana, tão bem como do território brasileiro, manifestações que vimos pondo em fo- 
co, ressalta de modo indiscutível a importância de nossas comunicações longitudinais, quer do ponto de vista da unidade brasileira, quer como fecho da projeção coordenadora do Brasil do ponto de vista continental (Travassos 1947, 158-159).

Em suma, essas diretrizes eram, para Travassos, a forma principal que faria prosperar o desenvolvimento e, consequentemente, uma hegemonia política e econômica do Brasil no continente sul-americano. E alertava o militar:

É preciso, desde já, que não se confunda a concisão da fórmula com o simplismo de uma arrancada para o sertão. Para o oeste! Não é voltar as costas para o mar e muito menos abrir luta contra o mar - por mais paradoxal que pareça, é estreitar a aliança com o mar, ampliando terras adentro a vinculação litorânea [...] três dos países andinos debruçam suas melhores esperanças sobre o amazonas, impelidos pela pobreza de articulação de suas costas estreitas, com o pacífico, cansados pela cabotagem entre o Canal do Panamá e o estreito de Magalhães, atraídos pelas bocas do rio-mar em contato majestoso com o Atlântico lhes estenda os braços por intermédio de nossas comunicações terrestres. [...] Para oeste! Como fórmula política de alto resultado, deve ser encarada como a resultante de um sistema de forças, como a direção geral de inúmeras atuações que vivem simultaneamente a solução dos mais graves problemas nacionais e a consecução do papel funcional que o espaço e a posição geográfica do Brasil lhe outorgam no continente e para além-mar (Travassos 1947, 245-248).

Na carona das ideias levantadas por Travassos em relação à expansão fronteiriça e a busca de um ponto crucial de domínio no continente, o nome do Brigadeiro Lysias Rodrigues e seus escritos sobre "geopolítica do Brasil” publicados em 1947 ganham destaque. As teorias geopolíticas de Rodrigues são, sem dúvida, "filhas" daquilo que se produziu no período anterior e constituem a retomada das premissas apresentadas por Travassos, porém reestruturadas para atender as nuances do período histórico em questão.

O mundo assistia, em 1947, o fim da guerra e com ela a emergência de dois blocos antagônicos de poder, porém semelhantes em proporções bélico-destrutivas. Se no plano internacional predominava a Guerra Fria, no plano interno efetivava-se a queda do Estado Novo. Por seu turno, o Presidente Eurico Gaspar Dutra, que assumia a presidência no momento de corte severo das relações com a União Soviética, sublinhou a oposição entre o "Brasil democrático" e a "Argentina totalitária". Iniciava-se, nesse período, o que Amado Cervo denomina "diplomacia da obstrução"; 
o Governo Dutra rejeitou as propostas de aproximação formuladas por Perón, o Parlamento não ratificou o convênio comercial bilateral de 1946 e o Itamaraty não endossou a proposta de aproveitamento conjunto dos rios. O encontro entre os dois Presidentes, em maio de 1947, limitou-se à inauguração protocolar da ponte Uruguaiana - Paso de los Libres, sem se desdobrar em uma conferência de cúpula, como desejado por Perón. Os acordos assinados na ocasião tampouco foram ratificados pelo Brasil. (Cervo 2003, 8-13)

Envolto nesse cenário em que as questões de hegemonia se fizeram presentes, os conceitos geopolíticos apresentados por Rodrigues foram marcados pela influência das ideias de Friedrich Ratzel, segundo as quais o mundo atingiria o limiar de uma idade imperial marcada pelas potências continentais. Rodrigues identificou no país áreas críticas compostas por forças distintas, contudo, localizadas em posição de suma importância, e por isso potencialmente causadoras de confrontos armados. Essas áreas, no caso, o Iguaçu, Bolívia e Letícia, representavam, de acordo, com o autor os "puncti dolentes":

A política da boa vizinhança? Os tratados internacionais? Não: Fale mais alto, mais positivamente, o impressionante problema dos "puncti dolentes sul-americanos, nova espada de Dámocles suspensa sobre o Brasil enquanto ele não puder resolvê-lo plenamente, ameaça perene enquanto o Brasil não puder neutralizá-los, se é que tal seja possível. Analisada a posição geográfica do Brasil no conjunto continental, e levando em consideração as enérgicas solicitações feitas sobre o conjunto pelos antagonismos geográficos, vemos que, ao Brasil cabe o papel de coordenador, sendo indiscutivelmente o "pivot" em torno do qual têm de girar todos os problemas deste continente sul-americano (Rodrigues 1947, 63).

O punctum dolens do Iguaçu viria a reforçar, no interior do discurso, o embate anunciado entre a Argentina e o Brasil pela dominação continental. Isso porque esse ponto, estrategicamente localizado na região da bacia do Prata - considerada entre os geopolíticos o ponto superior de tensão na América do Sul - faz fronteira entre os países citados, o que provocou, nessa região, um estrangulamento geográfico, por estar no meio da queda de braço entre brasileiros e argentinos. Ademais, o rio Iguaçu estaria situado no sistema fluvial platino que, de acordo com a geopolítica de Travassos, como já apresentamos, trazia vantagens aos argentinos e, consequentemente, deveria ser alvo de atenção do Brasil.

A ação dos fatores geopolíticos territoriais e geográficos, quer no Paraguai, quer na Argentina, criaram vetores de forças geopolíticas cujo ponto de aplicação localizou-se justamente em um ponto delica- 
do, aquele das grandes quedas d'água dos rios Paraná e Iguaçu, capazes de produzirem um elevado potencial elétrico, particularmente as primeiras, as mais importantes das quais admite um ponto de trijunção de fronteiras (Brasil, Argentina e Paraguai). [...] De fronteira viva que era essa região no Brasil Colônia, voltou a ser de novo fronteira viva, tal a pressão dos fatores geopolíticos. Sob as cinzas dormita o perigoso problema. Essa calma aparente é ilusória. No dia que premeditadamente ou sem má fé, alguém tocar no assunto do aproveitamento de tais quedas d'água, a ação dos fatores geopolíticos será de extrema violência, podendo provocar até uma guerra (Rodrigues $1947,64)$.

No caso do punctum dolens boliviano, Rodrigues não conseguiu avançar na discussão iniciada por Travassos e apenas deixou algumas impressões que apenas reforçaram as mesmas ideias:

De todos estes "punctum dolens", como muito acertadamente o apelidou Pandiá Calógeras, é o único que merece o epíteto de sul americano, porque ele é o ponto de aplicação das forças resultantes dos antagonismos oceânicos que solicitam o conjunto continental sul-americano. Situado no triângulo formado pelas cidades de SaucesCochabamba-Santa Cruz de La Sierra, região petrolífera por excelência, apresenta perigos que saltam à vista. (...). Nem aí descurou o Brasil de precaver-se contra ação dos fatores territoriais geopolíticos, pois, no extremo sul de Mato Grosso criou o Território Federal de Ponta Porã e empenhou-se vivamente na construção da ferrovia Brasil-Bolívia, já em adiantado estágio de construção e que em breve irá facilitar a derivação do escoamento dos produtos francamente para leste, para o Atlântico (Rodrigues 1947, 65-66).

A exemplo do exposto acima, o terceiro punctum dolens situava-se na região que abrange os Estados do Brasil, Peru e Colômbia respectivamente, todos eles próximos da cidade brasileira de Tabatinga. Essa região compreende um ponto estratégico localizado na vertente oriental com a bacia amazônica. Esse raciocínio corrobora com a tese de Travassos, de ser essa uma região essencial ao Brasil para garantia de sua supremacia no "antagonismo” Atlântico-Pacífico.

Essa região apresenta-se como um grande nó de diversos sistemas de transportes que buscam a porta de entrada do rio Amazonas nessa longínqua fronteira. Linhas de navegação fluvial e linhas aéreas comerciais, já trouxeram a essa região um impulso considerável, que cresce cada dia que passa, criando uma nova força de atração capaz de fazer fletir até ali rotas aéreas comerciais, que busquem ou venham da América do Norte, como fez o fator Canal do Panamá. [...] Em 
Letícia, como nos outros pontos, parece-nos que a primeira providência que se impõe é a criação ali de um outro território federal, capaz de vitalizar os elementos úteis que o Brasil ali dispõe, criando nesse ponto uma civilização brasileira predominantemente, como é justo (Rodrigues 1947, 66-67).

O entendimento dos punctum dolens serve à teoria de Rodrigues como instrumento de organização e reflexão que devem guiar a política internacional do Brasil; no interior da ideologia, eles, os dolens, são determinantes da projeção do Brasil em âmbito sul-americano e posteriormente mundial. Sendo assim, com o advento da Guerra Fria, as teorias geopolíticas se voltaram a pensar não só em estratégias e expansão imperial, mas principalmente na defesa do continente e do país contra as ações do comunismo internacional. Afirmamos que, principalmente no interior da caserna, criou-se um ramo da geopolítica dedicado exclusivamente a esse propósito. Lysias Rodrigues foi um dos primeiros autores a expressar em seu trabalho essa preocupação e colocá-la como central ao analisar o papel desempenhado pelo Brasil no continente. Segundo o autor, o embate entre o poder marítimo e terrestre era algo iminente, apenas uma questão de tempo para que a União Soviética, de posse do coração do mundo (heartland) e da Europa Oriental, estabelecesse um poder dominante em um bloco que compreendesse a Europa e a Ásia. Uma vez assegurada a supremacia do poder terrestre na Eurásia, o próximo passo soviético seria a conquista do norte da África e o estrangulamento das rotas do Atlântico, numa tentativa de aniquilar o poder marítimo norte-americano (Mello 1987, 116).

Dentro desse contexto expansionista soviético, Rodrigues acreditava que o Brasil, mais especificamente o Amazonas, compreendia o território perfeito para as ligações marítimas entre o Brasil e os Estados Unidos, ou seja, a partir dele o país poderia garantir uma eficiência maior nas suas defesas, "Assim, em território brasileiro, essa possível defesa da embocadura do rio Amazonas, o portão aberto daquela imensidade, só pode ser feita mais do que precariamente. É o nosso calcanhar de Aquiles”. (Rodrigues 1947, 116) A fragilidade dessa porção do território preocupava o militar, então, sua proposta visava fortalecer o dispositivo naquela área, anexando ao nosso território a Guiana Francesa, disse o geopolítico:

Para a França seria um alto negócio vender a Guiana Francesa, e para o Brasil, um negócio esplêndido adquiri-la. Não é preciso apontar o exemplo do Alaska adquirido pelos Estados Unidos. Não precisamos ir tão longe. $\mathrm{O}$ caso do Acre é bem semelhante (...) o Brasil comprando à França a Guiana Francesa, aliviaria em muito a inflação que o atinge, ajuntaria ao território nacional uma área considerável, 
mas, sobretudo, daria à embocadura do rio Amazonas a possibilidade de ter uma defesa eficiente (Rodrigues 1947, 117).

Na verdade, a incorporação da Guiana já representava em sua geopolítica o primeiro passo concreto para a projeção do Brasil no continente como uma potência dominante, líder na América Latina:

Dentro do conjunto continental sul-americano surge, porém, uma diretriz única, poderosa, geral, e que não podemos deixar de considerar em detalhe: Esta diretriz geopolítica é o Brasil que precisa criar na América do Sul um núcleo geopolítico poderoso, homogêneo, sob sua chefia política [...]. A formação pelo Brasil, de um subnúcleo geopolítico na América do Sul, sob sua direção, decorre logicamente do apoio que o Brasil precisa dar ao núcleo geopolítico do Atlântico, como meio de facilitar sua missão. A liderança do Brasil, também justifica plenamente, uma vez que o Brasil é na América do Sul, não só o país de maior área territorial, mas, o de maior população, o de maior projeção internacional política (Rodrigues 1947, 120-121).

Essa reivindicação do Brasil como uma potência em âmbito sul-americano passa ou está fundamentada, como já dissemos, na dimensão territorial e na densidade populacional do país; essa teoria é decorrência direta do determinismo e da filosofia da história à qual recorre Rodrigues. Tendo Ratzel como seu "mentor", o militar acreditava que o mundo marchava para a idade imperial, em que cada continente seria dominado por um grande Estado-suserano em torno do qual gravitaria uma gama de pequenos Estados-vassalos. E se o mundo seria dominado pelas grandes potências continentais, os recursos geográficos do Brasil capacitavam-no ao cargo.

Todas essas coisas, decorrem do estado de transição por que passa o mundo, para atingir a "idade imperial" prevista por Ratzel, a era da história continental, fixada pelas grandes potências que dominarem os grandes espaços. Nessa 'ida de imperial', ao Brasil cabe, sem dúvida alguma, papel preponderante. Pela vastidão de sua área territorial, pela sua posição geográfica esplêndida, pelos fatores geopolíticos benignos que o regem, pela imensa energia potencial latente que dispõe, e pela capacidade superior de seus homens, claramente evidenciada já, está o Brasil indicado para ser uma grande potência em prazo pouco dilatado. O Brasil tem conhecimento da lei geopolítica que estatui que, os grandes tratos de terra sob um mesmo domínio, forçam naturalmente a criação de um dogma imperialista local (Rodrigues 1947, 125).

Ainda sobre o papel de relevo do Brasil, Lysias Rodrigues estreita as relações com os norte-americanos quando diz: 
Na posição em que se acha o Brasil, as diretivas geopolíticas que o regem no plano mundial, são, pois: 1 - estreitar cada vez mais suas relações com os Estado Unidos; 2 - estimular a política da Boa Vizinhança; 3 - dar o mais cabal apoio ao núcleo geopolítico do Atlântico (Rodrigues 1947, 137-138).

Sendo assim, a aliança com os Estados Unidos não deveria ser eterna, mas uma pré-condição para a potência - visão assumida e difundida pelo general Golbery do Couto e Silva nas décadas de 1950 e 1960 no interior da Escola Superior de Guerra e posta em prática por Castelo Branco em 1964.

É inegável o papel fundamental da Escola Superior de Guerra na constituição, ainda que conjugada, de uma doutrina militar extensa. Apesar disso, no tratar das questões geopolíticas não se observava, pelo menos até o início dos anos 1950, uma articulação, no plano conceitual, entre os estudos geopolíticos e a Ideologia de Segurança Nacional. As primeiras discussões apresentadas na instituição traziam o general Golbery do Couto e Silva como expoente. Não obstante, essas “teorias” não apresentavam grandes superações aos ideólogos do período anterior; o cerne das formulações continuava a ser a expansão do Estado, a integração da nação e, consequentemente, a ideia chave de que espaço é poder. Desse modo, essa geopolítica continuou se orientando pelos pressupostos do Estado como um organismo vivo e movido por interesses autônomos em relação à sociedade, mas identificado agora com um ideal de nação que pretendia representar. Entretanto, para que os interesses do Estado fossem identificados com os da Nação, as diferenças sociais foram diluídas no plano ideológico e, no plano político, os conflitos subordinaram-se aos objetivos globais de domínio de poder.

Se essas visões faziam parte, como alertamos, dos estudos anteriores à ESG, o modo como a instituição se apropriou dessas concepções de Estado-Nação e tornou a geopolítica a base fundamental na constituição da "doutrina de segurança”, revelam outro momento desses estudos. Inaugurava-se, muito em razão do momento histórico propício somado a uma ideologia há muito viva no exército, uma geopolítica anticomunista e centrada na defesa da civilização "ocidental e cristã”. Desses dois fatores, iria emanar e/ou acrescentar os ideais de grandeza nacional, todavia, abocados cada vez mais aos norte-americanos. Onde pousava o destino manifesto do Brasil.

O livro no qual focamos nossa crítica, intitulado Geopolítica do Brasil, é uma coletânea de trabalhos mais densos ou artigos mais pontuais, produzidos pelo general entre 1950 e 1960. A escolha desse livro se justifica em 
dois momentos coligados: primeiro, o período em que estes escritos foram produzidos, pois trazem uma perspectiva ampla do decurso histórico e seus antagonismos, isso porque suas formulações estão impregnadas, externamente, pelo clima da Guerra Fria, da política de contenção dos Estados Unidos em relação à União Soviética e, internamente, a década que marcou os anos entre 1950 e 1960 foi extremamente conturbada, ou seja, iniciou-se com uma crise e terminou com outra. Contudo, desse período, o fator que mais ressonou na obra de Golbery foi a criação da Escola Superior de Guerra e sua "doutrina” de segurança nacional. Tendo sido publicado em 1967, indubitavelmente o cenário internacional fez parte das suas conclusões, nas quais as ações tidas como avanço do comunismo estavam mais latentes, os países europeus e o Japão estavam se reconstruindo economicamente e sobre esse ponto disse o geopolítico:

Assim sendo, esboço de uma geopolítica brasileira, este livro não exige, em verdade, rigorosa atualização. Tem a pretensão inerente a todo pensamento geopolítico que se preze, de resistir, em seu núcleo central de ideias, às variações conjunturais, mesmo em épocas de um dinamismo excepcional como a quadra que atravessamos. [...] E, pois, as mudanças sobrevindas no panorama internacional, não cremos que possam invalidar as ideias fundamentais que constituem o núcleo do pensamento geopolítico integrado que a seguir se exporá, nem tampouco venham a desfigurar, substancialmente, a perspectiva mundial em que se acha inserido (Couto e Silva 1967, 3-4).

O general afirmava que esses acontecimentos não afetariam a atualidade do seu pensamento, isso porque as variações conjunturais da década de 1960 não haviam caracterizado tantas mudanças - a bipolarização dos poderes representados pela União Soviética e os EUA continuavam a mesma. Assim sendo, nem o decréscimo da Guerra Fria, nem o fortalecimento do neutralismo do bloco terceiro-mundista, seriam, segundo Golbery, "determinantes capazes de alterar a visão de mundo, reafirmada pelo antagonismo entre Ocidente cristão e o Oriente comunista que dominava a conjuntura mundial”. (Couto e Silva 1967, 4)

No mundo de hoje, o antagonismo dominante entre os EUA e a Rússia, polarizando todo o conflito, de profundas raízes ideológicas, entre a civilização cristã do Ocidente e o materialismo comunista do Oriente, e no qual se joga pelo domínio ou pela libertação do mundo, arregimenta todo o planeta sob o seu dinamismo avassalante a que não podem, não poderão sequer escapar, nos momentos decisivos, os propósitos mais reiterados e honestos de um neutralismo, afinal de contas, impotente e obrigatoriamente oscilante (Couto e Silva 1981, 186-188). 
Não há dúvida de que a razão fundamental para esse embate entre os “dois mundos" era, segundo o autor, culpa do expansionismo soviético que por ter em suas mãos o coração do mundo, procuraram estabelecer um poder terrestre no bloco transcontinental euroasiático. $\mathrm{O}$ plano para conter o avanço soviético no ocidente, assim, buscava instrumentos numa política de contenção comandada pelos norte-americanos. Isso supunha que os EUA deveriam tomar posse de região entendida como Rimland - as fímbrias marítimas ou regiões periféricas que cercavam o heartland - para conter a expansão comunista. Essa estratégia apoiava-se em consistentes alianças políticas/militares organizadas pelos próprios norte-americanos no pós-guerra, além de uma rede de bases norte-americanas que formariam um cordão de isolamento.

E aí temos duas das ideias centrais da geopolítica golberyana: destino geopolítico, que ele reitera sempre proclamando que o grande heartland central, pelas sua simples e desnuda expressão espacial e a posição superior que desfruta no conjunto como centro natural da estrutura inteira, traz inscrito em si mesmo um destino imperial manifesto. Sendo assim:

Se a geografia atribui à costa brasileira e a seu promontório nordestino um quase monopólio de domínio no Atlântico Sul, esse monopólio é brasileiro, deve ser exercido por nós exclusivamente, por mais que estejamos, sem tergiversações, dispostos a utilizá-lo em benefício de nossos irmãos do norte, a que nos ligam tantos e tão tradicionais laços de amizade e de interesses, e em defesa ao mesmo tempo da civilização cristã, que é nossa, contra o imperialismo comunista de origem exótica. $[\ldots .$.$] também nós podemos invocar um destino ma-$ nifesto, tanto mais quanto ele não colide no Caribe com os nossos irmãos maiores do norte. [...] $\mathrm{E}$ se a velha Inglaterra soube reconhecer, desde cedo, o destino norte-americano, facilitando-lhe uma política de mãos livres no continente ocidental, à sombra protetora da esquadra britânica - a doutrina Monroe, como bem se sabe, foi inspirada por Canning - não parece demais que os EUA reconheçam também aquilo que devemos defender, a todo custo, como um direito inalienável, traçado pela própria natureza no mapa do Atlântico Sul (Couto e Silva 1981, 52).

A outra ideia é o expansionismo para o interior, sua propositura final, conforme teremos oportunidade de ver. Não obstante os muitos elementos negativos da avaliação, Golbery acreditava que

Evoluímos, pois - e não pouco -, da tênue colonização periférica que caracterizava ainda o Brasil nos começos do século XVII, para ocupação de ampla base de partida, favorável à manobra que teremos de realizar, da incorporação real do imenso domínio do interior, 
praticamente ainda o desertão, à comunidade nacional (Couto e Silva 1981, 73).

Golbery destacava veementemente que o Brasil, dono de vasto território, “é hoje um país territorialmente satisfeito”. Tendo, pois, seu espaço vital já conquistado, tratava-se de ocupá-lo e explorá-lo devidamente, o que contribuiria para superar a realidade do "profundo desequilíbrio econômico e cultural entre as regiões de seus diversos quadrantes, os vários brasis em que realmente se desdobra o panorama continental brasileiro". Assim, reafirmava que nossa geopolítica, ao menos naquele momento histórico, deveria ser "ainda uma geopolítica de expansionismo interior, de integração e valorização territoriais, sem quaisquer ressaibos de um imperialismo além-fronteiras descabido e grotesco para quem dispõe, dentro de seu habitat, de todo um território imenso a construir". (Couto e Silva 1981, 169-170)

E, sob profunda influência de Oliveira Vianna, conceituou seus dois brasis formados pelo ecúmeno - espaço valorizado efetivamente pela humanização, pouco mais que um terço do país -, e a oeste, o simples domínio, o Brasil marginal, inexplorado em sua maior parte, desvitalizado pela falta de gente e de energia criadora - a deixa para a retomada da proclamação de Mário Travassos: Para Oeste!

[...] o qual nos cumpre incorporar realmente à Nação, integrando-o na comunidade nacional e valorizando a sua grande expressão física hoje ainda quase completamente passiva. Tarefa sem dúvida gigantesca que está a exigir um planejamento cuidadoso e em longo prazo e que consumirá largos anos para sua realização, além de recursos vultosos de toda ordem (Couto e Silva 1981, 43).

\section{CONCLUSÃO}

Para além de uma conclusão, propomos estabelecer alguns pontos cruciais que permitam o estabelecimento de questionamentos caros ao tema.

Se for correto afirmar que momentos históricos diversos pedem soluções distintas, então não há dúvidas que o pensamento geopolítico brasileiro, de Travassos a Golbery, em pouco mais de duas décadas, operou de modo diferente em cada uma das situações históricas. Se numa primeira fase essa geopolítica militar esteve centrada nos elementos geográficos e na posição do Estado brasileiro frente a seus vizinhos, num segundo momento, com o advento da Escola Superior de Guerra na década de 1950 em fator da Guerra Fria -, o pensamento geopolítico trazia como bandeira 
a preocupação com a segurança nacional e a defesa do ocidente frente ao comunismo, entrelaçando a suas conjecturas as questões sobre segurança e desenvolvimento. Em que pesem as diferenças, como procuramos esmiuçar, os padrões que circundaram o discurso - unidade territorial, coesão nacional, posição e projeção do Brasil - estiveram todos ligados à busca de um papel de destaque do Brasil no cenário internacional, isto é, as bases de uma geopolítica de potência posteriormente aplicada pelo regime militar em determinados setores fincaram seus pilares nesses anos anteriores. A compreensão desses autores por nós apresentada se faz essencial na identificação de políticas aplicadas durante a ditadura, sobretudo nas regiões platina e amazônica.

Outro ponto basilar aos estudos sobre a geopolítica brasileira é justamente o seu caráter eminentemente militar. É necessário dizer que essa geopolítica militar voltada à construção de potência, apresentada na sua forma pura, é produto do tempo histórico em que foi produzida, assim como também são os autores que a produziram e remontam a uma tradição clássica. No entanto, não é possível compreender esse pensamento aqui no Brasil apenas como uma transposição de ideais ou de um modelo que foi seguido sem a devida crítica; dizemos isso porque o caminho percorrido pelas teorias clássicas da geopolítica até o momento em que se inserem de modo efetivo no Brasil é longo e só fazem sentido se entendermos que a formação desse pensamento efetivou-se a partir da instituição militar.

Não alongando muito a análise, é necessário destacar que o órgão militar se estruturou no Brasil tutelado pelo Estado Novo varguista e pela criação da Escola Superior de Guerra. Este último criou uma identidade militar até então inexistente e centralizou uma política sustentada na segurança estatal e no desenvolvimento econômico. Torna-se redundante ressaltar que o cenário internacional marcado pelo fim da Segunda Guerra Mundial e início da Guerra fria, abriram caminho para que ideologias autoritárias e centralizadoras que prometiam ser um instrumento de contra-ataque fossem bem recebidas pelos oficiais.

Comumente, a historiografia tradicional tende a dizer que a ideologia da segurança nacional - promulgada pelos Estados Unidos - foi absorvida como um bloco fechado de ideias. É preciso avançar nesta discussão demonstrando que os militares brasileiros procuraram fazer a devida adaptação para atender a realidade do país. Desse modo, é possível compreender que a noção de segurança nacional francesa, mais próxima da situação brasileira, foi melhor aceita, principalmente porque entre os fatores constitutivos da ideologia francesa, as potencialidades geográficas nacionais e a posição estratégica do país faziam ligação direta com o Brasil. O que levou os militares brasileiros a pensar - diferente do que a ideologia de segurança 
nacional norte-americana pregava - o Brasil como uma potência Mundial. Essa sem dúvida era a principal peculiaridade da ideologia de segurança nacional brasileira, isto é, pensava-se o Brasil potência a partir dela. Foi inclusive por esse fator que os estudos geopolíticos no Brasil foram incorporados à ideologia de segurança nacional. Ainda que os primeiros trabalhos tenham sido produzidos antes da Escola de Guerra, sua forma sistematizada e largamente divulgada só deu a partir de década de 1950.

E reafirmamos que, apesar da sistematização dos estudos só firmarem suas bases a partir da Escola Superior de Guerra, foram incorporadas todas as determinações desenvolvidas nos anos anteriores, como exemplo do pensamento de Mário Travassos e Lysias Rodrigues. E, como demonstramos, nesses autores já estavam expressas os ideias de potência, ainda não tão fortes como em 1960, mas já se pensava um Brasil como uma potência regional. Essa condição só iria mudar posteriormente, com o pensamento de Golbery do Couto e Silva na década de 1950, onde, em fator das condições já apresentadas, o Brasil passaria a ocupar na teoria do militar a categoria de co-potência junto com os norte-americanos.

\section{REFERÊNCIAS}

Backheuser, Everardo. 1926. A Estrutura Política do Brasil. I - Notas prévias. Rio de Janeiro: Mendonça, Machado \& Cia.

Bandeira, Moniz. 1978. Presença dos Estados Unidos no Brasil. Dois séculos de história. Rio de Janeiro: Civilização Brasileira.

Bandeira, Moniz. 1993. Estado nacional e política internacional na América Latina. O continente nas relações Argentina - Brasil (1930-1992). São Paulo: Ensaio.

Bastos, Pedro Z. 2001. A dependência em progresso: fragilidade financeira, vulnerabilidade comercial e crises cambiais no Brasil, 1890-1954. Tese de Doutorado. Campinas: IE-UNICAMP.

Cabral, Severino. 2000. Escola Superior de Guerra: Departamento de Estudos. Rio de Janeiro: Boletins da ESG.

Cervo, Amado Luiz. 2003. Política exterior e relações internacionais do Brasil: enfoque paradigmático. Brasília, Revista Brasileira de Política Internacional, v. 46 n. 2 jul./dez.

Costa, Wanderley Messias da. 2008. Geografia Politica e Geopolítica: discursos sobre território e poder. São Paulo: EDUSP. 
Couto e Silva, Golbery do. 1967. Geopolítica do Brasil. Rio de Janeiro: José Olympio. Couto e Silva, Golbery do. 1981. Planejamento estratégico. Brasília: Ed. UnB.

Hirst, Monica; Russell, Roberto. 1987. Democracia y política exterior: los casos de Argentina y Brasil. Buenos Aires, FLACSO, Série documentos e informes de investigación, n. 55.

Mello, L. I. A. 1987. Quem tem medo da geopolítica? São Paulo: Edusp/Hucitec.

Rodrigues, Lysias. 1947. Geopolítica do Brasil. Rio de Janeiro: Biblioteca Militar.

Schwartzmam, Simon; Bomeny, Maria Bousquet e Costa, Vanda Maria Ribeiro. 1984. Tempos de Capanema. Rio de Janeiro: Paz e Terra; São Paulo: Edusp.

Travassos, Mário. 1941. Estrutura geo-militar do Brasil. In: Cultura Política 1. Rio de Janeiro.

Travassos, Mário. 1947. Projeção Continental do Brasil. São Paulo: Companhia Editora Nacional.

Vesentini, José William. 1987. A Capital da Geopolítica. São Paulo: Editora Ática. 


\section{NOTAS}

1. Halford Jonh Mackinder (1864-1946) também ganhara a atenção dos estudiosos brasileiros não tanto pelo que tinha a oferecer, mas pelos problemas que colocava. Mackinder, após ter estudado a influência do espaço e da posição no condicionamento da política mundial, apresentou, em 1904, um trabalho intitulado "O Pivô Geográfico da História", uma tentativa de provar que o mundo é uma ilha controlada por um coração. Não há dúvidas que, para Mackinder, a nação pivô do mundo era a Inglaterra. Sendo assim, o geógrafo voltou suas preocupações aos dois países que faziam frente aos objetivos expansionistas ingleses, nesse caso a Alemanha de um lado e a Rússia de outro. Ao referir-se aos dois países, Mackinder alerta que a Rússia czarista ocupa, em face do mundo, a mesma posição estratégica central que a Alemanha dentro da Europa, então ambas podem atacar e/ou serem atacadas por todos os lados. O perigo que seria se a Alemanha e a Rússia se unissem visando à construção de uma esquadra que consequentemente levaria ao surgimento de um império do mundo.

2. Sobre o Brasil platino, Travassos o entende da seguinte maneira, "Na bacia platina, características concêntricas, suficiente homogeneidade e densidade de população, facilidades topográficas, condições meteorológicas favoráveis. Os peões se encontram em vantajosa posição inicial. Domínio absoluto da viação fluvial pela bandeira argentina. Estradas de ferro, em combinação com as vias navegáveis, procuram compensar a má posição da foz do Prata. Ambos os meios de comunicação drenando para Buenos Aires, como distribuidora, a economia dos Estados mediterrâneos e levando a influência platina até os vales longitudinais dos Andes." (Travassos 1947, 170). 


\section{GRANDE, SÓ O BRASIL: AS REGIÕES PLATINA E AMAZÔNICA NO CENTRO DO PENSAMENTO GEOESTRATÉGICO DO ESTADO}

\section{RESUMO}

Este artigo tem como objetivo, por meio da análise do conjunto de ideias apresentadas por militares e autores ligados às Forças Armadas em diferentes momentos, a saber, Everardo Backheuser, Lysias Rodrigues, Mario Travassos e Golbery do Couto e Silva, demonstrar que a configuração de um pensamento geopolítico brasileiro de potência se deu num constructo que equacionava as questões de segurança interno-externa à ideia de um desenvolvimento possível a partir das potencialidades e posição geográfica do Estado. Se, de um lado, procuraremos sustentar, a geopolítica brasileira remetia às influências vindas de fora, de outro, trazia como especificidade a identificação das regiões platina e amazônica como centro de um projeto de potência, o coração do continente, cujo domínio se fazia indispensável.

Palavras-chave: Geopolítica; Forças Armadas; Bacia do Prata; Bacia Amazônica.

\section{ABSTRACT}

This article analyses the set of ideas sustained by authors connected to the Brazilian armed forces like Everardo Backheuser, Lysias Rodrigues, Mario Travassos and Golbery do Couto e Silva. It argues that the Brazilian geopolitical thought tried to combine domestic and international security issues with development potentials streamed from the geography of the country. It also argues that, despite its foreign influences, Brazilian geopolitical thought was singular when proclaimed the control of the Amazon and the Platine basins as the core of its major power project.

Keywords: Geopolitics; Armed Forces; Prata Basin; Amazon Basin. 